\title{
Role of microRNA-29b in angiotensin II-induced epithelial- mesenchymal transition in renal tubular epithelial cells
}

\author{
JIALIN PAN $^{3 *}$, JUHONG ZHANG $^{1 *}$, XINGWEI ZHANG ${ }^{1}$, XI ZHOU ${ }^{2}$, SHENGYUE LU $^{2}$, \\ XIAOYAN HUANG ${ }^{1}$, JIAYU SHAO ${ }^{2}$, GUOQIANG LOU ${ }^{1}$, DEYE YANG ${ }^{1,2}$ and YONG-JIAN GENG ${ }^{4}$ \\ ${ }^{1}$ Division of Cardiology, The Affiliated Hospital of Hangzhou Normal University, Hangzhou, Zhejiang 310015; \\ ${ }^{2}$ Division of Cardiology, The First Affiliated Hospital of Wenzhou Medical University; ${ }^{3}$ Division of Cardiology, \\ The Second Affiliated Hospital of Wenzhou Medical University, Wenzhou, Zhejiang 325000, P.R. China; \\ ${ }^{4}$ The Center for Cardiovascular Biology and Atherosclerosis Research, The University of Texas \\ School of Medicine at Houston, Houston, TX 77030, USA
}

Received March 9, 2014; Accepted September 9, 2014

DOI: $10.3892 /$ ijmm.2014.1935

\begin{abstract}
Angiotensin II (Ang II) has been proven to induce epithelial-mesenchymal transition (EMT). The aim of the present study was to determine the role of microRNA-29b (miR-29b) during Ang II-induced EMT. For this purpose, we used spontaneously hypertensive rats (SHRs) and agematched Wistar-Kyoto (WKY) rats. The levels of Ang II and its receptor in the kidneys of the SHRs are significantly higher than those in the age-matched WKY rats. As shown by RT-qPCR, the expression of miR-29b in the renal cortex was lower in the SHRs than in the WKY rats. For in vitro experiments, NRK-52E renal tubular epithelial cells were treated with $10^{-7} \mathrm{M}$ Ang II; we found that the expression of miR-29b was decreased in the cells treated with Ang II. In addition, transfection of the NRK-52E cells with miR-29b inhibitor led to the downregulation of miR-29b in these cells, and increased the expression of transforming growth factor (TGF)- $\beta, \alpha$-smooth muscle actin ( $\alpha$-SMA) and collagen I (Col I). Similar results were observed with the induction of Ang II expression in the NRK-52E cells. By contrast, the upregulation of miR-29b by transfection with miR-29b mimics inhibited the overexpression of these genes induced by Ang II. These results suggest that miR-29b plays an important role in Ang II-induced EMT.
\end{abstract}

Correspondence to: Professor Deye Yang, Division of Cardiology, The Affiliated Hospital of Hangzhou Normal University, 126 Wenzhou Ave., Hangzhou, Zhejiang 310015, P.R. China E-mail: deyeyang203@hotmail.com

${ }^{*}$ Contributed equally

Keywords: microRNA-29b,angiotensinII,NRK-52Ecells, epithelialmesenchymal transition, spontaneously hypertensive rats

\section{Introduction}

MicroRNAs (miRNAs or miRs) are small endogenous RNAs that modulate gene expression by targeting the 3 untranslated regions (3' UTRs) of mRNAs to inhibit translation or promote mRNA degradation $(1,2)$. In recent years, the miR-29 family has been implicated in the fibrosis of multiple organs (3). Spontaneously hypertensive rats (SHRs) are an ideal animal model of hypertension. The kidneys of adult SHRs express high levels of extracellular matrix (ECM) proteins, $\alpha$-smooth muscle actin ( $\alpha$-SMA) and matrix metalloproteinases (MMPs) than age-matched Wistar-Kyoto (WKY) rats (4). This indicates that the kidneys of adult SHRs have already developed fibrosis.

Angiotensin II (Ang II), the main peptide of the reninangiotensin-aldosterone system (RAAS), plays an important role in the occurrence and development of hypertension, as well as in epithelial-mesenchymal transition (EMT), which is a crucial step in the development of renal fibrosis. In the kidneys of young SHRs, the levels of Ang II, as well as those of its receptor are significantly higher than those in WKY rats $(5,6)$. Ang II increases the expression and the synthesis of ECM proteins, including multiple collagens and fibrillins (7). In the present study, we aimed to determine whether miR-29b is the downstream gene of Ang II and to elucidate its role in Ang II-induced EMT.

\section{Materials and methods}

Rats and measurement of blood pressure. Male (15 weeks old) SHRs and age-matched WKY rats were acquired from the Chinese Academy of Sciences, Shanghai, China. They were housed under standardized conditions with controlled temperature $\left(20-26^{\circ} \mathrm{C}\right)$ and humidity (40-70\%) and exposed to a $12-\mathrm{h}$ light/dark cycle. Systolic blood pressure (SBP) was measured by the tail-cuff method using a PowerLab data acquisition and analysis system (ADInstruments Inc., Sydney, Australia) under slightly restrained and quiet conditions for 5 days prior to the experiments. The average of 3 pressure readings was recorded. The animal study was approved by the Animal 
Welfare Committee of Wenzhou Medical University following state and institutional regulations.

$R T-q P C R$ analysis of miR-29b expression in the renal cortex. Total RNA was extracted from the renal cortex of SHRs and WKY rats using TRIzol reagent (Invitrogen, Carlsbad, CA, USA). The purity of the total RNA was determined using a spectrophotometer (DU800; Beckman Coulter, Miami, FL, USA) and its quality was determined by formaldehyde denaturation gel electrophoresis. The miRNAs were isolated and purified using the miRNA isolation kit (Ambion). The reverse transcription of the miRNAs was performed using the miScription Reverse Transcription kit (Qiagen, Valencia, CA, USA) according to the manufacturer's recommendations. The miRNA specific real-time quantitative polymerase chain reaction (RT-qPCR) primers were used in RT-qPCR together with the miScript Universal Primer which was included in the kit. The sequence of the rno-miR-29b specific primer was 5'-TAGCACCATTTGAAATCAGTGTT-3', and that of the U6 primer was 5'-CAAGGATGACACGCAAATTCG-3'. The PCR reaction was performed using the ABI 7500 Fast RealTime PCR System (Applied Biosystems, Bedford, MA, USA). The amplification program was $95^{\circ} \mathrm{C}$ for $15 \mathrm{~min}$ and then 40 cycles consisting of $95^{\circ} \mathrm{C}$ for $10 \mathrm{sec}$ and $60^{\circ} \mathrm{C}$ for $35 \mathrm{sec}$. The relative amount of miR-29b was normalized to that of the U6 RNA. The ABI Prism 7900HT Sequence Detection System (Applied Biosystems, Foster City, CA, USA) was used to analyze the data, and the $\Delta \Delta \mathrm{CT}$ method was used to calculate the relative expression of the sample gene. The relative quantification (RQ) of gene expression was analyzed using the $2^{-\Delta \Delta C T}$ method, as previously described (8): $R Q=2^{-\Delta \Delta C T}$ (CT indicates the cycles required by the fluorescence signal intensity to reach the threshold value in the PCR amplification process, $\Delta \mathrm{CT}_{\text {sample }}=\mathrm{CT}_{\text {sample }}-\mathrm{CT} \mathrm{U6} 6_{\text {sample }}, \Delta \mathrm{CT}_{\text {control }}=\mathrm{CT}_{\text {control }}-\mathrm{CT}$ $\left.\mathrm{U6}_{\text {control }}, \Delta \Delta \mathrm{CT}=\Delta \mathrm{CT}_{\text {sample }}-\Delta \mathrm{CT}_{\text {control }}\right)$. The experiment was repeated 3 times.

Cell line. The renal tubular epithelial cells line (NRK-52E) was obtained from the Cell Bank of the Chinese Academy of Sciences. The NRK-52E cells were cultured in Dulbecco's modified Eagle's medium (DMEM) (low glucose; Gibco-BRL, Gaithersburg, MD, USA) containing 5\% fetal bovine serum (FBS; Gibco-BRL) and incubated in a humidified atmosphere of $95 \% \mathrm{O}_{2}, 5 \% \mathrm{CO}_{2}$ at $37^{\circ} \mathrm{C}$ in a $\mathrm{CO}_{2}$ incubator. When the cells grew to $90 \%$ confluency, they were then harvested by a brief exposure to $0.05 \%$ trypsin-EDTA (Gibco-BRL) and passaged every 3 days.

Treatment with Ang II. The NRK-52E cells were cultured into 6 -well plates at the density of $1 \times 10^{5}$ cells/well. They were then divided into 2 groups: the Ang II group (treatment with $10^{-7}$ M Ang II) and the blank control (BC) group (without extra treatment). The following experiments were carried out after the cells were cultured at $37^{\circ} \mathrm{C}$ in an incubator containing $5 \%$ $\mathrm{CO}_{2}$ for 24 or $48 \mathrm{~h}$.

RT-qPCR analysis of miR-29b expression in the Ang II and blank control group. Total RNA was extracted using TRIzol reagent (Invitrogen). The purity and quality of the total RNA were determined as described above. The microRNA isolation kit (Ambion) was used to detach small molecular RNA less than $100 \mathrm{nt}$, and the miScript Reverse Transcription kit (Qiagen) was used to synthesize the cDNA through reverse transcription. The PCR conditions and the method of data analysis were as described above. The experiment was repeated 3 times.

Synthesis of miR-29b mimics and miR-29b inhibitor. The positive-sense strand of miR-29b mimics (Sigma-Aldrich, St. Louis, MO, USA) was as follows: 5'-UAGCACCAUUUGA AAUCAGUGUU-3' and its antisense strand was 5'-CACUG AUUUCAAAUGGUGCUAUU-3', having no homology with the rat genome. The positive-sense strand of the miR-29b inhibitor (Sigma-Aldrich) was as follows: 5'-AACACUGA UUUCAAAUGGUGCUA-3' and its antisense strand was 5'-CAGUACUUUUGUGUAGUACAA-3', having no homology with the rat genome.

Flow cytometry for the assessment of the transfection efficiency. A total of $5 \mu \mathrm{l}$ FAM-NC miRNA/5 $\mu \mathrm{l}$ Lipofectamine $^{\mathrm{TM}} 2000$ (Invitrogen) was transfected into the NRK-52E cells. The transfection efficiency was assessed using a flow cytometer (Becton-Dickinson, San Jose, CA, USA) $24 \mathrm{~h}$ following transfection.

Transfection with miR-29b inhibitor and miR-29b mimics. miR-29b was either downregulated or upregulated in the NRK-52E cells by transfection with miR-29b inhibitor or miR-29b mimics, respectively. A single-cell suspension was prepared and the cells were cultured in 6-well plates at the density of $1 \times 10^{5}$ cells/well $24 \mathrm{~h}$ prior to transfection. The NRK-52E cells were transfected using Lipofectamine 2000 (Invitrogen) according to the manufacturer's instructions. For the downregulation, the cells were divided into 3 groups: downregulation (DR) group (transfection with miR-29b inhibitor), negative control (NC) group (transfection with miRNA synthesized randomly) and the blank control (BC) group (no transfection). For the upregulation, the cells were divided into 4 groups: the upregulation (UR) group (transfection with miR-29b and treatment with $10^{-7} \mathrm{M}$ Ang II $24 \mathrm{~h}$ following transfection), the negative control- ${ }_{\text {Ang II }}\left(\mathrm{NC}_{\text {Ang II }}\right)$ group (transfection with miRNA synthesized randomly and treatment with $10^{-7} \mathrm{M}$ Ang II $24 \mathrm{~h}$ following transfection), the Ang II group (treatment with $10^{-7} \mathrm{M}$ Ang II) and the blank control (BC) group. The following experiments were carried out after the cells were cultured at $37^{\circ} \mathrm{C}$ in an incubator containing $5 \% \mathrm{CO}_{2}$ for 24 or $48 \mathrm{~h}$.

$R T-q P C R$ analysis of miR-29b, transforming growth factor (TGF)- $\beta, \alpha$-SMA and collagen (Col) I expression following transfection. Total RNA was extracted through the one-step method with TRIzol reagent (Invitrogen) $24 \mathrm{~h}$ after transfection and the cells were cultured until they reached $70-80 \%$ confluence. The purity and quality of the total RNA were determined as described above. The methods and steps of reverse transcription, PCR amplification and data analysis for miR-29b were as described above. The RevertAid ${ }^{\mathrm{TM}}$ First Strand cDNA Synthesis kit (Thermo Fisher Scientific Inc., Waltham, MA, USA) was adopted to synthesize cDNA through reverse transcription. The RT-qPCR primers (synthesized by Invitrogen) are presented in Table I. The PCR reaction was performed using the ABI 7500 Fast Real-Time PCR System. 
Table I. Primers used for RT-qPCR.

\begin{tabular}{|c|c|}
\hline mRNA & Primer sequences \\
\hline \multirow[t]{2}{*}{$\alpha$-SMA } & Forward: CTTCTATAACGAGCTTCGC \\
\hline & Reverse: TCCAGAGTCCAGCACAAT \\
\hline \multirow[t]{2}{*}{ TGF- $\beta$} & Forward: AGGCGGTGCTCGCTTTGT \\
\hline & Reverse: GATTGCGTTGTTGCGGTCC \\
\hline \multirow[t]{2}{*}{ Col I } & Forward: ACTCAGCCCTCTGTGCCT \\
\hline & Reverse: CCTTCGCTTCCATACTCG \\
\hline \multirow[t]{2}{*}{ MMP-2 } & Forward: AGCTCCCGGAAAAGATTGAT \\
\hline & Reverse: TCCAGTTAAAGGCAGCGTCT \\
\hline \multirow[t]{2}{*}{$\beta$-actin } & Forward: GAGGGAAATCGTGCGTGAC \\
\hline & Reverse: AGGAAGGAAGGCTGGAAG \\
\hline
\end{tabular}

$\alpha$-SMA, $\alpha$-smooth muscle actin; TGF- $\beta$, transforming growth factor- $\beta$; Col I, collagen I; MMP-2, matrix metalloproteinase 2.

The relative amount of each mRNA was normalized to that of $\beta$-actin using the $2^{-\Delta \mathrm{CT}}$ method. The amplification program was $95^{\circ} \mathrm{C}$ for $10 \mathrm{~min}$ and then 40 cycles consisting of $95^{\circ} \mathrm{C}$ for $15 \mathrm{sec}$ and $60^{\circ} \mathrm{C}$ for $60 \mathrm{sec}$. The relative amount of each mRNA was normalized to that of $\beta$-actin. The ABI Prism 7900HT Sequence Detection System (SDS 2.2.2 software) was used to analyze the data, and $\Delta \Delta \mathrm{CT}$ method was used to calculate the relative expression of the sample gene. The relative quantification (RQ) of gene expression was analyzed by the $2^{-\Delta \Delta \mathrm{CT}}$ method as follows: $\mathrm{RQ}=2^{-\Delta \Delta \mathrm{CT}}\left(\Delta \mathrm{CT}_{\text {sample }}=\mathrm{CT}_{\text {sample }}-\mathrm{CT}_{\beta \text {-actin sample }}\right.$, $\left.\Delta \mathrm{CT}_{\text {control }}=\mathrm{CT}_{\text {control }}-\mathrm{CT}_{\beta \text {-actin control }}, \Delta \Delta \mathrm{CT}=\Delta \mathrm{CT}_{\text {sample }}-\Delta \mathrm{CT}_{\text {control }}\right)$. The experiment was repeated 3 times.

Western blot analysis of the protein expression of TGF- $\beta$, $\alpha$-SMA and Col Ifollowing transfection. Forty-eight hours after transfection, the cells were washed twice with ice-cold PBS and then lysed in $200 \mu 1$ of ice-cold lysis buffer (RIPA:PMSF, 99:1; Sigma). The cells lysates were lysed further by ultrasound. The lysates were then centrifuged at $15,000 \mathrm{x} \mathrm{g}$ for $15 \mathrm{~min}$ at $4^{\circ} \mathrm{C}$, and the supernatants were collected and stored at $-80^{\circ} \mathrm{C}$. The protein concentration was determined by BCA protein assay (Beyotime, Jiansu, China). The lysates (30 $\mu \mathrm{g}$ of protein) were separated on $10 \%$ polyacrylamide gels using SDS-PAGE and transferred onto nitrocellulose (NC) membranes. After transferring, the membranes were blocked for $2 \mathrm{~h}$ at $4^{\circ} \mathrm{C}$ with $5 \%$ skimmed milk, incubated overnight at $4^{\circ} \mathrm{C}$ with each primary antibody (rabbit anti- $\alpha$-SMA antibody 1:500 dilution; rabbit anti-TGF- $\beta$ antibody 1:300 and rabbit anti-Col I antibody 1:500 dilution; Abcam, Bristol, UK), washed 3 times in TBST buffer, incubated with secondary antibody [at 1:4,000 dilution, goat anti-rabbit IgG $(\mathrm{H}+\mathrm{L})$ IRDye ${ }^{\circledR} 800 \mathrm{CW}$; LI-COR Biosciences, Lincoln, NE, USA] for $2 \mathrm{~h}$ at room temperature and washed 3 times in TBST buffer. The blots were analyzed using the Odyssey Infrared Imaging System (Li-COR Biosciences). The relative amount of protein on each blot was normalized to that of $\beta$-actin, and the semi-quantitative analysis of the blots was carried out using the AlphaEaseFC Imaging System (Alpha
Innotch,San Leandro,CA, USA). The experiment was repeated at least 3 times.

Analysis of SMA and Col I expression by immunofluorescence staining. The NRK-52E cells were fixed in $4 \%$ paraformaldehyde solution, permeabilized with $0.5 \%$ Triton $\mathrm{X}-100$ for $10 \mathrm{~min}$, blocked for $45 \mathrm{~min}$ with $5 \%$ serum at room temperature, incubated overnight at $4^{\circ} \mathrm{C}$ with primary antibodies (rabbit anti- $\alpha$-SMA antibody 1:200 dilution; rabbit anti-Col I antibody 1:100 dilution; Abcam), washed 3 times in PBS, incubated with DyLight 549 conjugated donkey anti-rabbit antibodies (1:500; Jackson ImmunoResearch Laboratories West Grove, PA, USA) at $37^{\circ} \mathrm{C}$ for $1 \mathrm{~h}$ and washed 4 times in PBS. The cells were then stained with 4',6-diamidino-2-phenylindole to visualize the nuclear content. Fluorescence images were acquired using a laser scanning confocal microscope (Carl Zeiss, Jena, Germany).

Statistical analysis. The data were analyzed using SPSS 18.0 software. All experiments were repeated 3 times and the results are presented as the means \pm SE. Differneces between multiple groups were analyzed by one-way ANOVA followed by Tukey's post hoc comparisons. Differences were considered statistically significant at $\mathrm{P}<0.05$.

\section{Results}

Blood pressure measurement. The average SBP of the SHRs and WKY rats was $191.3 \pm 16.6$ and $121.8 \pm 14.7 \mathrm{mmHg}$, respectively, and the difference between them was statistically significant $(\mathrm{P}<0.05)$.

Differential expression of $\mathrm{miR}-29 \mathrm{~b}$ in the renal cortex between the SHRs and WKY rats. RT-qPCR revealed that the expression of miR-29b in the renal cortex of the SHRs $(0.76 \pm 0.01)$ was significantly lower than that of the WKY rats $(1.00 \pm 0.00)$ $(\mathrm{P}<0.05)$.

Ang II downregulates miR-29b expression. The expression of miR-29b in the NRK-52E cells was confirmed by RT-qPCR following treatment with $10^{-7} \mathrm{M}$ Ang II. The expression of miR-29b in the Ang II group (0.56 \pm 0.06$)$ was significantly downregulated compared with that of the blank control (BC) group $(1.00 \pm 0.00)$.

Transfection with miR-29b inhibitor upregulates the expression levels of TGF- $\beta, \alpha-S M A$ and $\mathrm{Col} I$. To further examine the function of miR-29b, the NRK-52E cells were transfected with miR-29b inhibitor. The transfection efficiency was determined by flow cytometry $24 \mathrm{~h}$ after $5 \mu \mathrm{FAM}-\mathrm{NC}$ miRNA/ $5 \mu \mathrm{l}$ Lipofectamine 2000 were transfected into the NRK-52E cells. The results of flow cytometry revealed that the transfection efficiency of the NRK-52E cells was $95.14 \%$ (Fig. 1).

The results of miR-29b RT-qPCR revealed that the expression level of miR-29b was significantly lower in the downregulation (DR) group than in the negative control (NC) and blank control (BC) group $(\mathrm{P}<0.05)$, while there was no statistically significant difference between the latter 2 groups ( $\mathrm{P}>0.05)$ (Fig. 2A).

The results of RT-qPCR also revaled that the mRNA expression levels TGF- $\beta, \alpha$-SMA and Col I in the DR group were significantly higher than those of the $\mathrm{BC}$ and $\mathrm{NC}$ group 

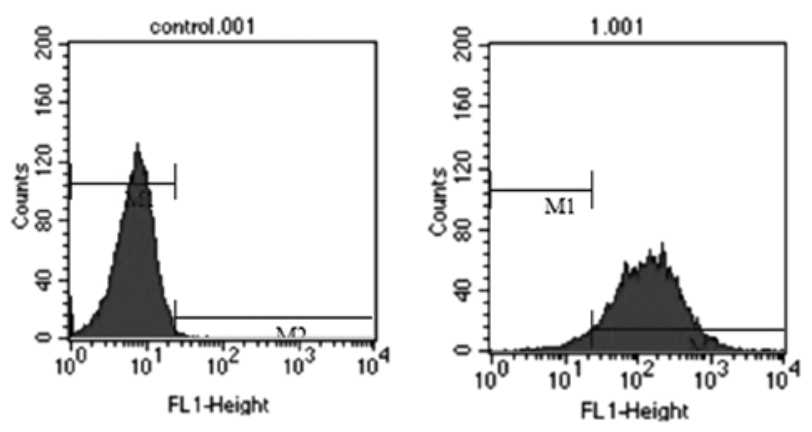

Figure 1. Transfection efficiency of NRK-52E cells following transfection with miR-29b inhibitor detected by flow cytometry. (Left panel) Blank control group of NRK-52E cells (transfection efficiency, 0.25\%); (right panel) NRK-52E cells transfected with inhibitor (transfection efficiency, 95.14\%).

$(\mathrm{P}<0.05)$, while there was no statistically significant difference between the latter 2 groups ( $\mathrm{P}>0.05)$ (Fig. 2B).

The results of western blot analysis indicated that the protein expression levels of TGF- $\beta, \alpha$-SMA and Col I in the DR group were significantly higher than those of the $\mathrm{BC}$ and $\mathrm{NC}$ group $(\mathrm{P}<0.05)$, while there was no statistically significant difference between the latter 2 groups ( $\mathrm{P}>0.05$ ) (Fig. 2C).

The results of immunofluorescence staining also revealed that the expression levels of $\alpha$-SMA and $\mathrm{Col} I$ in the DR group were significantly higher than those of the $\mathrm{BC}$ and $\mathrm{NC}$ group (Fig. 2D and E).

Transfection with miR-29b mimics downregulates the expression levels of TGF- $\beta, \alpha-S M A$ and Col I. The NRK-52E cells were transfected with miR-29b mimics, and treated with Ang II $\left(10^{-7} \mathrm{M}\right)$ following transfection. The results of RT-qPCR demonstrated that the expression level of miR-29b was markedly higher in upregulation (UR) group than in the $\mathrm{NC}_{\mathrm{Ang} \text { II }}$ and Ang II group $(\mathrm{P}<0.05)$, while there was no statistically significant difference between the latter 2 groups $(\mathrm{P}>0.05)$ (Fig. 3A).

The results of real-time PCR revealed that the mRNA expression levels of TGF- $\beta, \alpha$-SMA and Col I were significantly lower in the UR group than in the Ang II and $\mathrm{NC}_{\mathrm{Ang} \text { II }}$ group, while there was no statistically significant difference between the latter 2 groups ( $\mathrm{P}>0.05)$; the expression levels of both these latter groups were significantly higher than the levels of the $\mathrm{BC}$ group (Fig. 3B).

The results of western blot analysis indicated that the protein expression levels of TGF- $\beta, \alpha$-SMA and Col I were significantly lower in the UR group than in the Ang II and $\mathrm{NC}_{\text {Ang II }}$ group $(\mathrm{P}<0.05)$, while there was no statistically significant difference between the latter 2 groups $(\mathrm{P}>0.05)$; the expression levels of both these latter groups were significantly higher than the levels of the $\mathrm{BC}$ group $(\mathrm{P}<0.05)$ (Fig. 3C).

The results of immunofluorescence staining revealed that the expression levels of $\alpha$-SMA and Col I in the UR group were significantly lower than those of the Ang II and $\mathrm{NC}_{\mathrm{Ang} \text { II }}$ group (Fig. 3D and E).

\section{Discussion}

The present study demonstrated that the expression level of $\mathrm{miR}-29 \mathrm{~b}$ in the renal cortex of SHRs was decreased compared with age-matched WKY rats. Ang II induced the downregulation of miR-29b in the NRK-52E cells in vitro, and we hypothesized that low level of miR-29b expression in the renal cortex of SHRs may be related to the high level of Ang II. We came to this hypothesis on the basis of the study of Matsushima et al (6), who demonstrated that the levels of Ang II and the density of Ang II receptor in the kidneys of young SHRs were significantly higher than those of age-matched WKY rats. We also thus hypothesized that the downregulation of miR-29b expression may have a similar effect on NRK-52E cells as that observed following treatment with Ang II, while the upregulation of miR-29b expression may protect NRK-52E cells from EMT induced by Ang II.

The expression level of miR-29b in the renal cortex between adult SHRs and WKY rats was analyzed by RT-qPCR. We found that the expression level of miR-29b in the SHRs was decreased compared with that of the WKY rats. The study of Matsushima et al mentioned above testified high levels of Ang II and its receptor in the kidneys of SHRs. In our study, we treated NRK-52E cells with Ang II in vitro, and found (by RT-qPCR) that this induced the downregulation of miR-29b. Ang II promotes renal fibrosis by increasing the expression of fibrosisassociated genes, such as TGF- $\beta, \alpha$-SMA and Col I (9-12). In recent years, a number of studies have demonstratd the effects of miR-29b on fibrosis (13-15). However, to the best of our knowledge, it has rarely been reported that Ang II regulates miR-29b expression. Liu et al (16) reported that Ang II induced renal functional injury and fibrosis through the upregulation of SP1 and the downregulation of miR-29b expression, while Smad7 may play a protective role in Ang II-induced hypertensive kidney injury. These data and the data presented in our study suggest that Ang II decreases the expression level of miR-29b. Possibly, the low levels of miR-29b expression in the renal cortex of SHRs may be related to the high levels of Ang II. However, the specific mechanisms involved remain unclear. We hypothesized that at least two distinct intracellular signaling pathways are involved. One pathway involves nuclear factor- $\kappa \mathrm{B}$ (NF- $\kappa \mathrm{B})$ activated by Ang II by binding to type I angiotensin II receptor (AT1R) $(17,18)$. NF- $\kappa \mathrm{B}$ activates another transcription factor, YY1, which directly combines with the promoter of miR-29b2/c to suppress its expression (19). Another pathway involves mitogen-activated protein kinase (MAPK) activated by the Ang II-phospholipase C (PLC)-protein kinase C (PKC) signaling pathway; MAPK activates proto-oncogene c-myc, which directly binds to the promoter of miR-29b2/c to suppress its expression (20-22).

EMT is an important step in the process of renal fibrosis. TGF- $\beta$ has been acknowledged to play an important role in EMT by inducing the expression of $\alpha$-SMA, which is an important marker of EMT and stimulates the production of ECM, including Col I and Col III $(15,23,24)$. To further examine the function of miR-29b,NRK-52E cells were transfected with miR-29b inhibitor. The results of RT-qPCR, western blot analysis and immunofluorescence staining revealed that miR-29b inhibitor induced a marked upregulation in the expression of TGF- $\beta, \alpha$-SMA and $\mathrm{Col} \mathrm{I}$ in the NRK-52E cells. Our data suggest that the downregulation of miR-29b expression promotes EMT. Members of the miR-29 family are negatively regulated by TGF- $\beta / \mathrm{Smad} 3$ and play a protective role in renal fibrosis by inhibiting the deposition of ECM and preventing EMT $(25,26)$. At present, only approxi- 
A

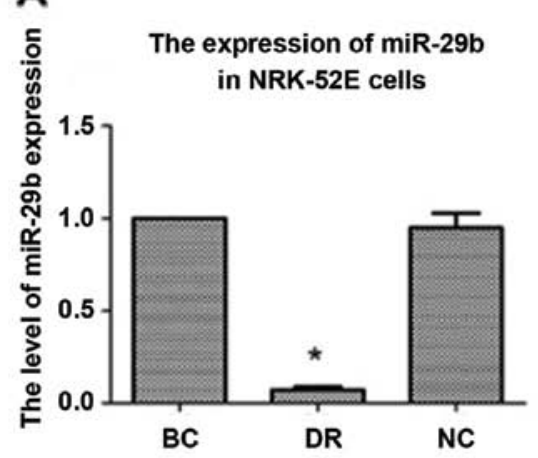

C

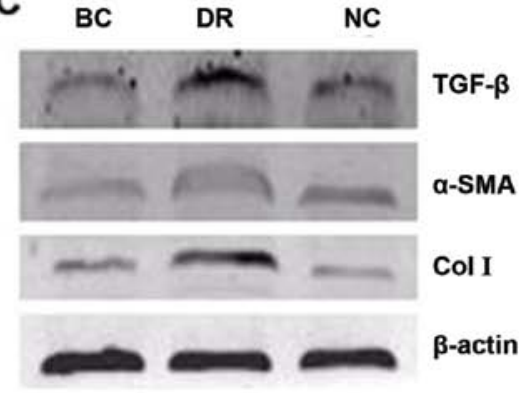

B
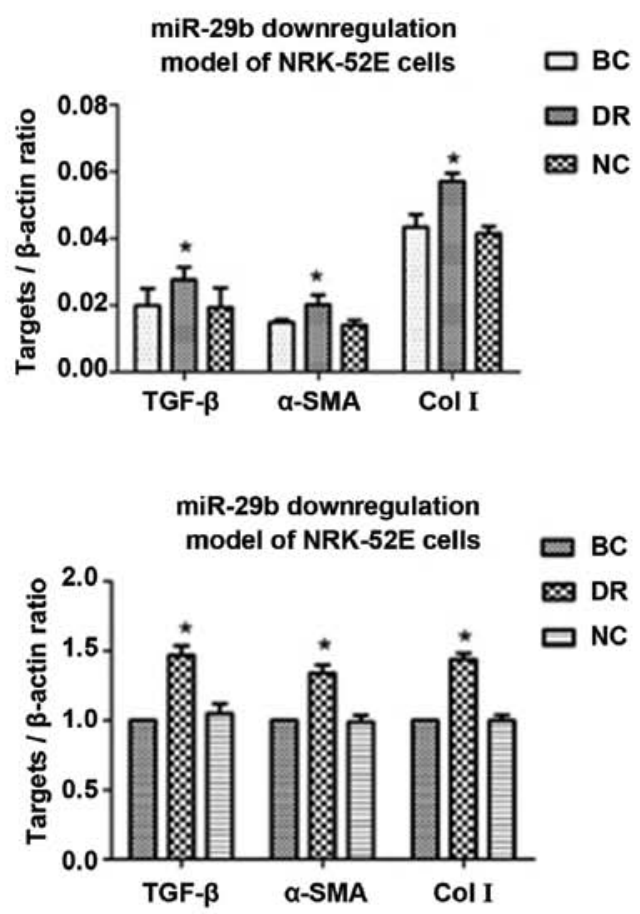

D
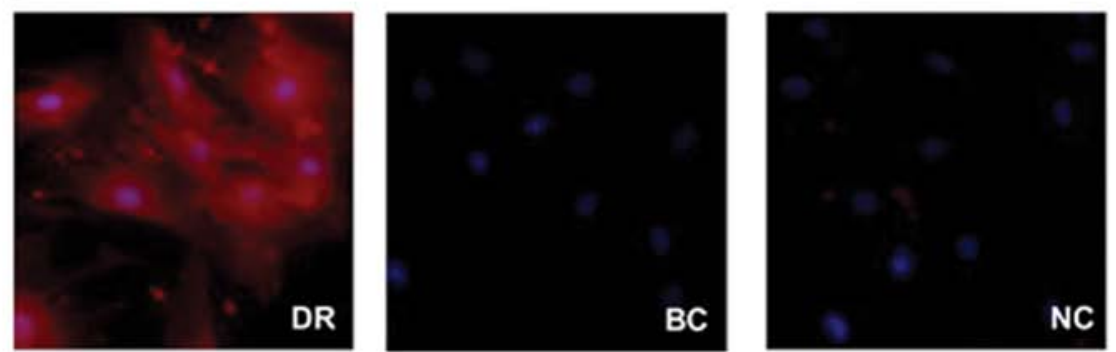

E
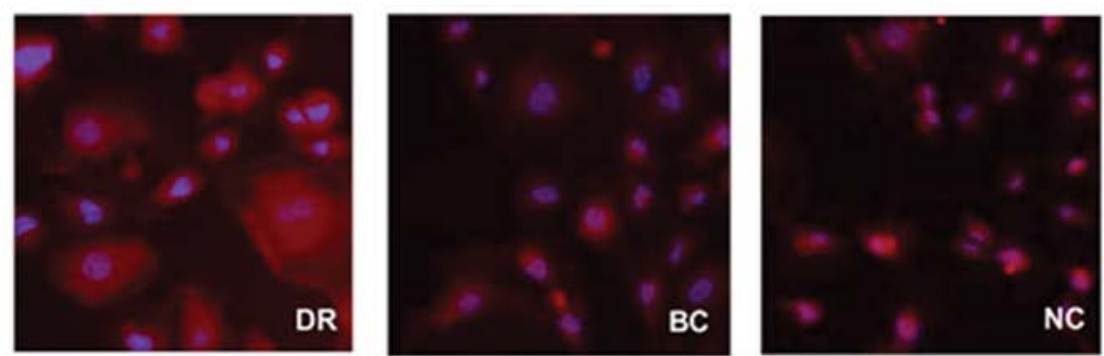

Figure 2. Expression levels of miR-29b, transforming growth factor (TGF)- $\beta$, $\alpha$-smooth muscle actin ( $\alpha$-SMA) and collagen I (Col I) analyzed by RT-qPCR, western blot analysis and immunofluorescence staining following downregulation of miR-29b. (A) RT-qPCR analysis of miR-29b expression; ${ }^{*} \mathrm{P}<0.05$ compared with the BC group and NC group. (B) RT-qPCR analysis of TGF- $\beta, \alpha$-SMA and Col I expression; " $\mathrm{P}<0.05$ compared with the BC group and NC group. (C) Western blot analysis of TGF- $\beta, \alpha$-SMA and Col I expression; representative blots show TGF- $\beta, \alpha$-SMA and Col I; ${ }^{*} \mathrm{P}<0.05$ compared with the BC group and NC group. (D) Immunofluorescence staining of $\alpha$-SMA; representative images demonstrating the fluorescence of $\alpha$-SMA protein (red) and nuclear (blue) expression in NRK-52E cells in the different groups. (E) Immunofluorescence staining of Col I; representative images demonstrating the fluorescence of Col I protein (red) and nuclear (blue) expression in NRK-52E cells in the different groups. BC, blank control group; DR, downregulation group (transfection with miR-29b inhibitor); NC, negative control group.

mately 40 target genes of 7,000 candidates which were predicted by miRNA target prediction software (PicTar, TargetScan and miRBase) have been confirmed, chief among these were ECM genes, such as various collagens, fibrillin, elastin and protocadherin $(12,15,19,24,27,28)$.
Furthermore, in our study, NRK-52E cells were transfected with miR-29b mimics and treated with Ang II $24 \mathrm{~h}$ following transfection. The results of RT-qPCR, western blot analysis and immunofluorescence staining demonstrated that the overexpression of miR-29b markedly suppressed the Ang II-induced 
A

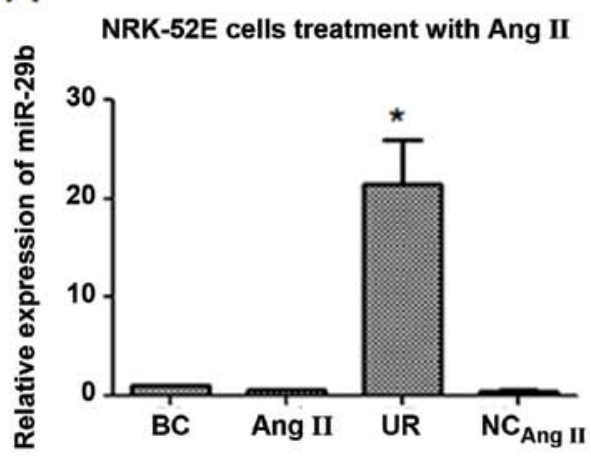

C

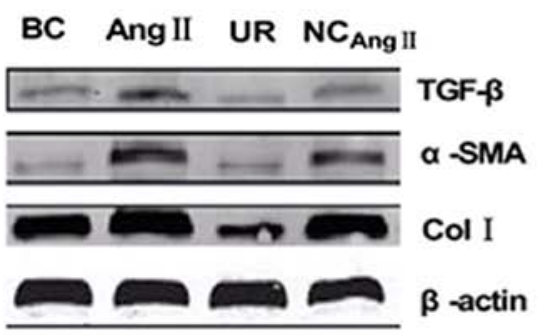

B
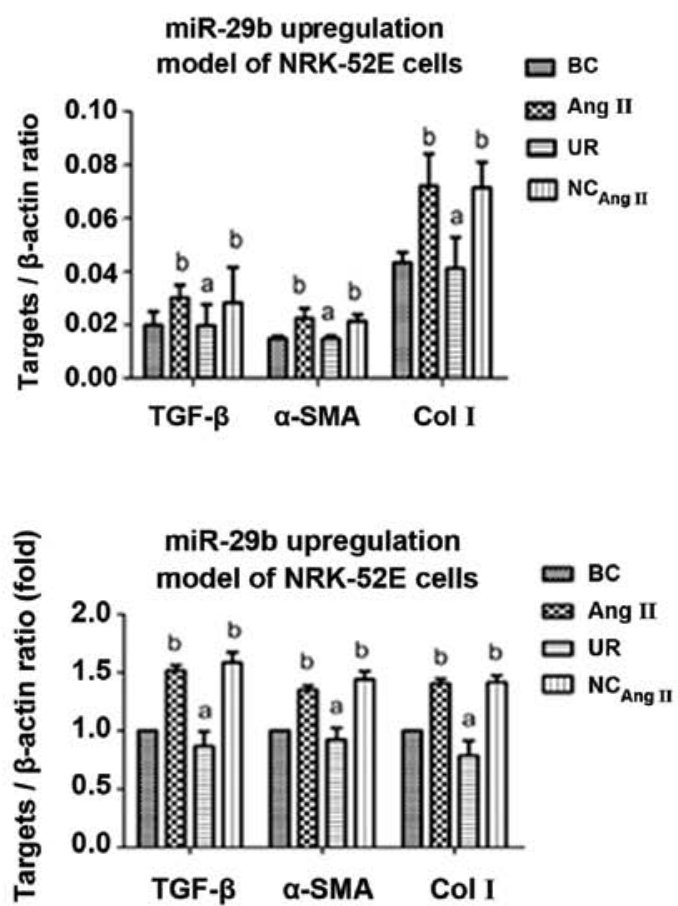

D
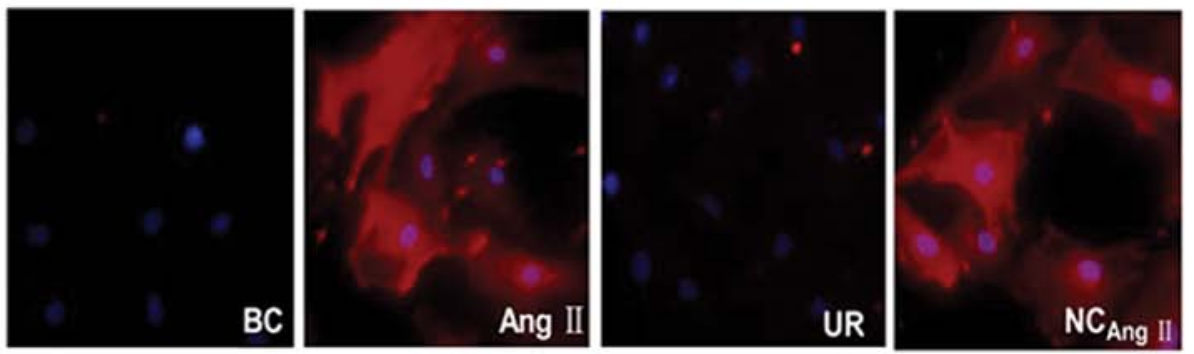

E
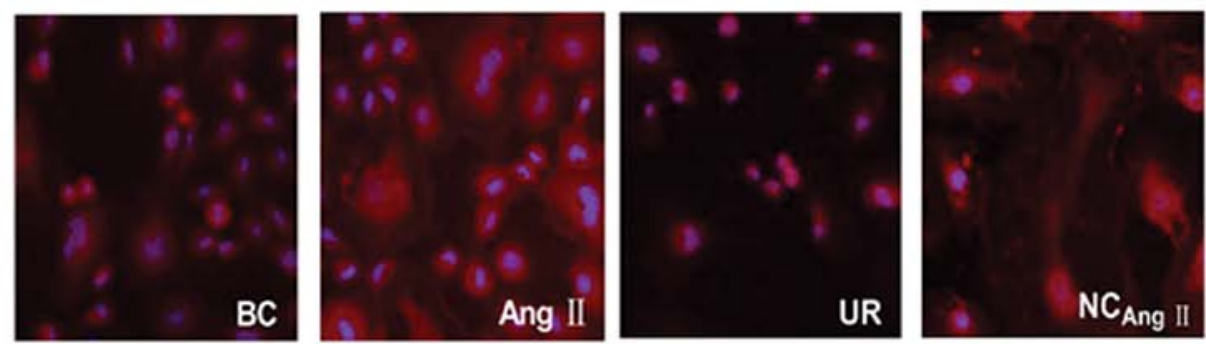

Figure 3. Expression levels of miR-29b, transforming growth factor (TGF)- $\beta, \alpha$-smooth muscle actin ( $\alpha$-SMA) and collagen I (Col I) analyzed by RT-qPCR, western blot analysis and immunofluorescence staining following upregulation of miR-29b $24 \mathrm{~h}$ before treatment with $10^{-7} \mathrm{M}$ angiotensin II (Ang II). (A) RT-qPCR analysis of miR-29b expression; ${ }^{*} \mathrm{P}<0.05$ compared with the Ang II group and $\mathrm{NC}_{\mathrm{Ang} \text { II }}$ group. (B) RT-qPCR analysis of TGF- $\beta$, $\alpha$-SMA and Col I expression; ${ }^{a} \mathrm{P}<0.05$ compared with the Ang II group and $\mathrm{NC}_{\mathrm{Ang} \text { II }}$ group; ${ }^{\mathrm{b}} \mathrm{P}<0.05$ compared with the $\mathrm{BC}$ group. (C) Western blot analysis of TGF- $\beta, \alpha-\mathrm{SMA}$ and Col I expression; representative blots show TGF- $\beta, \alpha-\mathrm{SMA}$ and $\mathrm{Col} \mathrm{I}$; ${ }^{\text {a }} \mathrm{P}<0.05$ compared with the Ang II group and NC ${ }_{\mathrm{Ang} \text { II }}$ group; ${ }^{\text {b }} \mathrm{P}<0.05$ compared with the $\mathrm{BC}$ group. (D) Immunofluorescence staining of $\alpha$-SMA; representative images demonstrating the fluorescence of $\alpha$-SMA protein (red) and nuclear (blue) expression in NRK-52E cells in the different groups. (E) Immunofluorescence staining of Col I; representative images demonstrating the fluorescence of Col I protein (red) and nucleus (blue) in NRK-52E cells in different groups. BC, blank control group; Ang II, Ang II group (treatment with $10^{-7} \mathrm{M}$ Ang II); UR, upregulation group (transfection with miR-29b mimics $24 \mathrm{~h}$ before treatment with $10^{-7} \mathrm{M}$ Ang II ); $\mathrm{NC}_{\mathrm{Ang}}$, negative control-Ang II group (without transfection $24 \mathrm{~h}$ before treatment with $10^{-7} \mathrm{M}$ Ang II).

upregulation of TGF- $\beta, \alpha-$ SMA and Col I. These results suggest that the overexpression of miR-29b negatively modulates EMT. miR-29 regulates multiple signal pathways, such as the TGF- $\beta$ / Smad (15), NF- $\kappa$ B $(19,22)$, Wnt/ $\beta$-catenin (29) and MAPK (30) pathways, by suppresing the expression of target genes. The
TGF- $\beta /$ Smad pathway is considered the most important. Luna et al (31) found that the overexpression of miR-29b inhibited fibrosis by suppressing TGF- $\beta 1$ expression at the mRNA and protein level. miR-29b directly suppresses the expression of ECM proteins, such as various collagens, fibrillin, elastin and 
protocadherin $(27,28)$. These data, as well as the data presented in our study illustrate that miR-29b negatively modulates EMT. Moreover, Ang II induces the downregulation of miR-29b expression and promotes NRK-52E cells to undergo EMT. The downregulation of miR-29b has a similar effect on NRK-52E cells as that observed following treatment with Ang II, while the upregulation of miR-29b protects NRK-52E cells from Ang II-induced EMT.

\section{Acknowledgements}

The present study was supported by a grant from the Ministry of Health of the People's Republic of China Science Foundation (wkj2008-2-031).

\section{References}

1. Cesana M, Cacchiarelli D, Legnini I, Santini T, Sthandier O, Chinappi M, Tramontano A and Bozzoni I: A long noncoding RNA controls muscle differentiation by functioning as a competing endogenous RNA. Cell 147: 358-369, 2011.

2. Choi YJ, Lin CP, Ho JJ, He X, Okada N, Bu P, Zhong Y, Kim SY, Bennett MJ, Chen C, Ozturk A, Hicks GG, Hannon GJ and He L: miR-34 miRNAs provide a barrier for somatic cell reprogramming. Nat Cell Biol 13: 1353-1360, 2011.

3. Wang G, Kwan BC, Lai FM, Chow KM, Li PK and Szeto CC: Urinary miR-21, miR-29, and miR-93: novel biomarkers of fibrosis. Am J Nephrol 36: 412-418, 2012.

4. Lekgabe ED, Kiriazis H, Zhao C, Xu Q, Moore XL, Su Y, Bathgate RA, Du XJ and Samuel CS: Relaxin reverses cardiac and renal fibrosis in spontaneously hypertensive rats. Hypertension 46: 412-418, 2005 .

5. Cheng HF, Wang JL, Vinson GP and Harris RC: Young SHR express increased type 1 angiotensin II receptors in renal proximal tubule. Am J Physiol 274: F10-F17, 1998.

6. Matsushima Y, Kawamura M, Akabane S, Imanishi M, Kuramochi M, Ito K and Omae T: Increases in renal angiotensin II content and tubular angiotensin II receptors in prehypertensive spontaneously hypertensive rats. J Hypertens 6: 791-796, 1988.

7. Mezzano SA, Ruiz-Ortega M and Egido J: Angiotensin II and renal fibrosis. Hypertension 38: 635-638, 2001.

8. Livak KJ and Schmittgen TD: Analysis of relative gene expression data using real-time quantitative PCR and the $2^{-\Delta \Delta C T}$ Method. Methods 25: 402-408, 2001.

9. Jimenez E, Perez de la Blanca E, Urso L, Gonzalez I, Salas J and Montiel M: Angiotensin II induces MMP 2 activity via FAK/JNK pathway in human endothelial cells. Biochem Biophys Res Commun 380: 769-774, 2009.

10. Lavoz C, Rodrigues-Diez R, Benito-Martin A, Rayego-Mateos S, Rodrigues-Diez RR, Alique M, Ortiz A, Mezzano S, Egido J and Ruiz-Ortega M: Angiotensin II contributes to renal fibrosis independently of Notch pathway activation. PLoS One 7: e40490, 2012.

11. Pons M, Cousins SW, Alcazar O, Striker GE and MarinCastano ME: Angiotensin II-induced MMP-2 activity and MMP-14 and basigin protein expression are mediated via the angiotensin II receptor type 1-mitogen-activated protein kinase 1 pathway in retinal pigment epithelium: implications for agerelated macular degeneration. Am J Pathol 178: 2665-2681, 2011.

12. Zhong J, Guo D, Chen CB, Wang W, Schuster M, Loibner H, Penninger JM, Scholey JW, Kassiri Z and Oudit GY: Prevention of angiotensin II-mediated renal oxidative stress, inflammation, and fibrosis by angiotensin-converting enzyme 2. Hypertension 57: 314-322, 2011.
13. Cushing L, Kuang PP, Qian J, Shao F, Wu J,Little F, Thannickal VJ, Cardoso WV and Lu J: miR-29 is a major regulator of genes associated with pulmonary fibrosis. Am J Respir Cell Mol Biol 45: 287-294, 2011.

14. Qin W, Chung AC, Huang XR, Meng XM, Hui DS, Yu CM, Sung JJ and Lan HY: TGF- $\beta / \mathrm{Smad} 3$ signaling promotes renal fibrosis by inhibiting miR-29. J Am Soc Nephrol 22: 1462-1474, 2011.

15. Roderburg C, Urban GW, Bettermann K, Vucur M, Zimmermann H, Schmidt S, Janssen J, Koppe C, Knolle P, Castoldi M, Tacke F, Trautwein C and Luedde T: Micro-RNA profiling reveals a role for miR-29 in human and murine liver fibrosis. Hepatology 53: 209-218, 2011.

16. Liu GX, Li YQ, Huang XR, Wei L, Chen HY, Shi YJ, Heuchel RL and Lan HY: Disruption of Smad7 promotes ANG II-mediated renal inflammation and fibrosis via Sp1-TGF- $\beta /$ Smad3-NF.кBdependent mechanisms in mice. PLoS One 8: e53573, 2013.

17. Han Y, Runge MS and Brasier AR: Angiotensin II induces interleukin-6 transcription in vascular smooth muscle cells through pleiotropic activation of nuclear factor- $\kappa \mathrm{B}$ transcription factors. Circ Res 84: 695-703, 1999.

18. Kranzhofer R, Schmidt J, Pfeiffer CA, Hagl S, Libby P and Kubler W: Angiotensin induces inflammatory activation of human vascular smooth muscle cells. Arterioscler Thromb Vasc Biol 19: 1623-1629, 1999.

19. Wang H, Garzon R, Sun H, Ladner KJ, Singh R, Dahlman J, Cheng A, Hall BM, Qualman SJ, Chandler DS, Croce CM and Guttridge DC: NF- $\kappa \mathrm{B}-\mathrm{YY} 1-\mathrm{miR}-29$ regulatory circuitry in skeletal myogenesis and rhabdomyosarcoma. Cancer Cell 14: 369-381, 2008.

20. Chang TC, Yu D, Lee YS, Wentzel EA, Arking DE, West KM, Dang CV, Thomas-Tikhonenko A and Mendell JT: Widespread microRNA repression by Myc contributes to tumorigenesis. Nat Genet 40: 43-50, 2008.

21. Mott JL, Kurita S, Cazanave SC, Bronk SF, Wemeburg NW and Femandez-Zapico ME: Transcriptional suppression of mir-29b-1/mir-29a promoter by c-Myc, hedgehog, and NF-kappaB. J Cell Biochem 110: 1155-1164, 2010.

22. Sadoshima J and Izumo S: Signal transduction pathways of angiotensin II - induced c-fos gene expression in cardiac myocytes in vitro. Roles of phospholipid-derived second messengers. Circ Res 73: 424-438, 1993.

23. Kopp JB: TGF- $\beta$ signaling and the renal tubular epithelial cell: too much, too little, and just right. J Am Soc Nephrol 21: 1241-1243, 2010

24. Meng XM, Huang XR, Chung AC, Qin W, Shao X, Igarashi P, Ju W, Bottinger EP and Lan HY: Smad2 protects against TGF- $\beta$ /Smad3-mediated renal fibrosis. J Am Soc Nephrol 21: 1477-1487, 2010.

25. Chung AC, Yu X and Lan HY: MicroRNA and nephropathy: emerging concepts. Int J Nephrol Renovasc Dis 6: 169-179, 2013.

26. Patel V and Noureddine L: MicroRNAs and fibrosis. Curr Opin Nephrol Hypertens 21: 410-416, 2012.

27. Fort A, Borel C, Migliavacca E, Antonarakis SE, Fish RJ and Neerman-Arbez M: Regulation of fibrinogen production by microRNAs. Blood 116: 2608-2615, 2010.

28. Villarreal G Jr, Oh DJ, Kang MH and Rhee DJ: Coordinated regulation of extracellular matrix synthesis by the microRNA-29 family in the trabecular meshwork. Invest Ophthalmol Vis Sci 52: 3391-3397, 2011.

29. Kapinas K, Kessler CB and Delany AM: miR-29 suppression of osteonectin in osteoblasts: regulation during differentiation and by canonical Wnt signaling. J Cell Biochem 108: 216-224, 2009.

30. Inoki K, Haneda M, Ishida T, Mori H, Maeda S, Koya D, Sugimoto T and Kikkawa R: Role of mitogen-activated protein kinases as downstream effectors of transforming growth factorbeta in mesangial cells. Kidney Int Suppl 77: S76-S80, 2000.

31. Luna C, Li G, Qiu J Epstein DL and Gonzalez P: Cross-talk between miR-29 and transforming growth factor-betas in trabecular meshwork cells. Invest Ophthalmol Vis Sci 52: 3567-3572, 2011. 